\title{
MR-Based Assessment of Bone Marrow Fat in Osteoporosis, Diabetes, and Obesity
}

\author{
Christian Cordes ${ }^{1 *}$, Thomas Baum ${ }^{1}$, Michael Dieckmeyer ${ }^{1}$, Stefan Ruschke', \\ Maximilian N. Diefenbach ${ }^{1}$, Hans Hauner ${ }^{2}$, Jan S. Kirschke ${ }^{3}$ and Dimitrios C. Karampinos ${ }^{1}$ \\ 'Department of Diagnostic and Interventional Radiology, Klinikum rechts der Isar, Technische Universität München, Munich, \\ Germany, ${ }^{2}$ Else Kröner Fresenius Center for Nutritional Medicine, Klinikum rechts der Isar, Technische Universität München, \\ Munich, Germany, ${ }^{3}$ Section of Diagnostic and Interventional Neuroradiology, Klinikum rechts der Isar, Technische Universität \\ München, Munich, Germany
}

Bone consists of the mineralized component (i.e., cortex and trabeculae) and the non-mineralized component (i.e., bone marrow). Most of the routine clinical bone imaging uses X-ray-based techniques and focuses on the mineralized component. However, bone marrow adiposity has been also shown to have a strong linkage with bone health.
OPEN ACCESS

Edited by:

William Peter Cawthorn, University of Edinburgh, UK

Reviewed by:

Graham J. Galloway,

Translational Research Institute, Australia

Miriam A. Bredella,

Massachusetts General Hospital,

USA

*Correspondence: Christian Cordes

c.cordes@tum.de

Specialty section: This article was submitted to Bone Research, a section of the journal Frontiers in Endocrinology

Received: 19 April 2016 Accepted: 14 June 2016 Published: 27 June 2016

Citation:

Cordes C, Baum T, Dieckmeyer M, Ruschke S, Diefenbach MN, Hauner H, Kirschke JS and Karampinos DC (2016) MR-Based Assessment of Bone Marrow Fat in Osteoporosis, Diabetes, and Obesity.

Front. Endocrinol. 7:74. doi: 10.3389/fendo.2016.00074 Specifically, multiple previous studies have demonstrated a negative association between bone marrow fat fraction (BMFF) and bone mineral density. Magnetic resonance imaging (MRI) and magnetic resonance spectroscopy (MRS) are ideal imaging techniques for non-invasively investigating the properties of bone marrow fat. In the present work, we first review the most important MRI and MRS methods for assessing properties of bone marrow fat, including methodologies for measuring BMFF and bone marrow fatty acid composition parameters. Previous MRI and MRS studies measuring BMFF and fat unsaturation in the context of osteoporosis are then reviewed. Finally, previous studies investigating the relationship between bone marrow fat, other fat depots, and bone health in patients with obesity and type 2 diabetes are presented. In summary, $\mathrm{MRI}$ and MRS are powerful non-invasive techniques for measuring properties of bone marrow fat in osteoporosis, obesity, and type 2 diabetes and can assist in future studies investigating the pathophysiology of bone changes in the above clinical scenarios.

Keywords: bone marrow, magnetic resonance imaging, magnetic resonance spectroscopy, osteoporosis, diabetes, obesity

\section{INTRODUCTION}

Bone consists of the mineralized (i.e., cortex and trabeculae) and the non-mineralized component (i.e., bone marrow). The interaction of the mineralized and non-mineralized components plays an important role in bone loss pathophysiology. Quantitative measurements of the mineralized component have been traditionally performed by using dual-energy-X-ray-absorptiometry (DXA) or quantitative computed tomography (QCT) assessing bone mineral density (BMD) (1). $\mathrm{BMD}$ is used in clinical routine to determine osteoporosis-associated fracture risk. Osteoporosis is defined as a skeletal disorder characterized by compromised bone strength predisposing an individual to an increased risk for fractures (2). It is classified as a public health problem, since osteoporosis-related fractures are associated with a reduction in quality of life and an increased 
morbidity and mortality $(3,4)$. However, BMD accounts for only $60-70 \%$ of the variation in bone strength (5) and the BMD values of subjects with and without osteoporotic fracture overlap (6). Measurements of trabecular bone microstructure, based on high-resolution imaging techniques, in addition to BMD have shown to improve the prediction of the variation in bone strength (7-9).

Despite the focus on the mineralized bone component for osteoporosis diagnostics, recent studies have highlighted the potential role of the non-mineralized bone component in bone health (10-14). Bone marrow fills the cavities of trabecular bone and it primarily consists of adipocytes (yellow marrow regions) or adipocytes and hematopoietic red blood cells (red marrow regions). It is well known that osteoporosis is associated with an increased bone marrow fat mass due to a shift of differentiation of mesenchymal stem cells to adipocytes rather than to osteoblasts $(11,13,15)$. Multiple studies have shown that higher bone marrow fat fraction (BMFF) values are associated with lower BMD values $(12,14,16-26)$.

Bone marrow fat has a distinctly different function compared to other white and brown adipose tissue depots or ectopic fat depots in the human body (27) and might play a role in the pathophysiology of metabolic disorders. Metabolic diseases, including obesity and diabetes, are known to have a complex and still poorly understood relationship to bone health. There seems to be a higher fracture-related morbidity in obese than in nonobese women (28), and more fractures in diabetic than in healthy subjects (29-32). In addition, there is a growing interest to study the relationship between bone marrow fat mass and fat in other depots regarding obesity and type 2 diabetes mellitus (T2DM).

In this context, imaging biomarkers are emerging to non-invasively study the properties of the non-mineralized component of bone (33). Dual-energy CT (DECT) allows to simultaneously determine bone marrow fat and BMD (34). In contrast to DECT, magnetic resonance (MR) allows the quantitative assessment of bone marrow without radiation exposure. $\mathrm{MR}$ enables reliable measurements of bone marrow water-fat and fatty acid composition with different methods including magnetic resonance imaging (MRI) and magnetic resonance spectroscopy (MRS) $(35,36)$.

The purpose of the present work is to review the currently available literature on MR-based assessment of bone marrow fat in the context of osteoporosis, T2DM, and obesity.

\section{MR-BASED ASSESSMENT OF BONE MARROW FAT}

\section{Literature Research}

Electronic searches in PubMed (http://www.ncbi.nlm.nih.gov/ pubmed) were performed up to March 2015 to identify relevant studies for this review. No starting date was entered for the electronic search to obtain the entire literature available in PubMed. Search terms used included "Bone Marrow," "Bone Marrow Fat," "Bone Marrow Adipose Tissue," "Magnetic Resonance Imaging," "Magnetic Resonance Spectroscopy," "Osteoporosis," "Obesity," and "Diabetes." The search was restricted to studies in humans. The reference lists of relevant articles were also screened.

\section{MR Methods}

T1-weighted imaging (T1WI), MRS, and chemical shift encoding-based water-fat imaging have been previously used to assess BMFF.

\section{T1-Weighted Imaging}

T1-weighted imaging is not technically demanding and has been mostly applied on the pelvis, hip, and spine. A recent study has even introduced a score analog to the DEXA $t$-score based on the mean signal-to-noise ratio of the L1-L4 vertebral bodies in T1WI (37). Measurements of bone marrow fat volume have been also proposed by applying thresholds on T1WI to extract bone marrow fat voxels (25). The applied threshold was usually set at the same gray-scale level as subcutaneous adipose tissue. The intra- and interobserver reproducibility for the assessment of bone marrow fat volume in T1WI images expressed as coefficient of variation (CV) amounted $0.9 \%$ (intraobserver) and 2.2\% (interobserver) (for the post-processing) (38). The main error source for the calculation of bone marrow fat volume based on T1WI results from partial volume effects and threshold selection, especially in regions with red marrow.

\section{Magnetic Resonance Spectroscopy}

Proton-MRS (1H-MRS) is considered as the MR gold standard for bone marrow fat quantification (Figure 1). Point-resolved spectroscopy (PRESS) and stimulated echo acquisition mode (STEAM) single-voxel 1H-MRS sequences have been most commonly used for the characterization of the fat spectrum in the bone marrow at the pelvis, spine, and hip. Based on MR spectra, fat fraction and fatty acid composition parameters can be determined (36). The average CV of vertebral BMFF was reported to be $1.7 \%$ (on the same day with repositioning). Griffith et al. recruited 36 subjects who underwent MRS in the femoral neck and head, as well as in the subtrochanteric region of the femoral shaft to measure bone marrow fat content (39). They found the best reproducibility (between two measurements within 1 week) in the femoral head (interclass correlation 0.85 ), followed by the femoral shaft (interclass correlation 0.83), and the femoral neck (interclass correlation 0.78). Another recent study that examined reproducibility of $1 \mathrm{H}$-MRS vertebral BMFF found a CV of $9.9 \%$ (SD 0.08) for a 6-week reproducibility and a CV of $12.3 \%$ (SD 0.10 ) for a 6 -month reproducibility (40).

However, most of the above studies did not account for the difference in $\mathrm{T} 2$ relaxation times between the water- and fat components and measured a signal-weighted fat fraction at a single echo time (TE), dependent on the employed TE value and field strength. A multi-TE MRS measurement combined with T2 estimation routines instead removes the confounding effects of water-fat T2 differences and results in the proton density fat fraction (PDFF), which is independent of the employed experimental settings (41).

In addition, bone marrow spectra are characterized by strongly overlapping water and fat peaks due to susceptibility effects from the trabecular bone $(41,42)$ : water and olefinic fat peaks overlap significantly, especially in the spine. The a priori knowledge of the chemical structure of triglycerides can be employed to improve the robustness of water peak extraction 

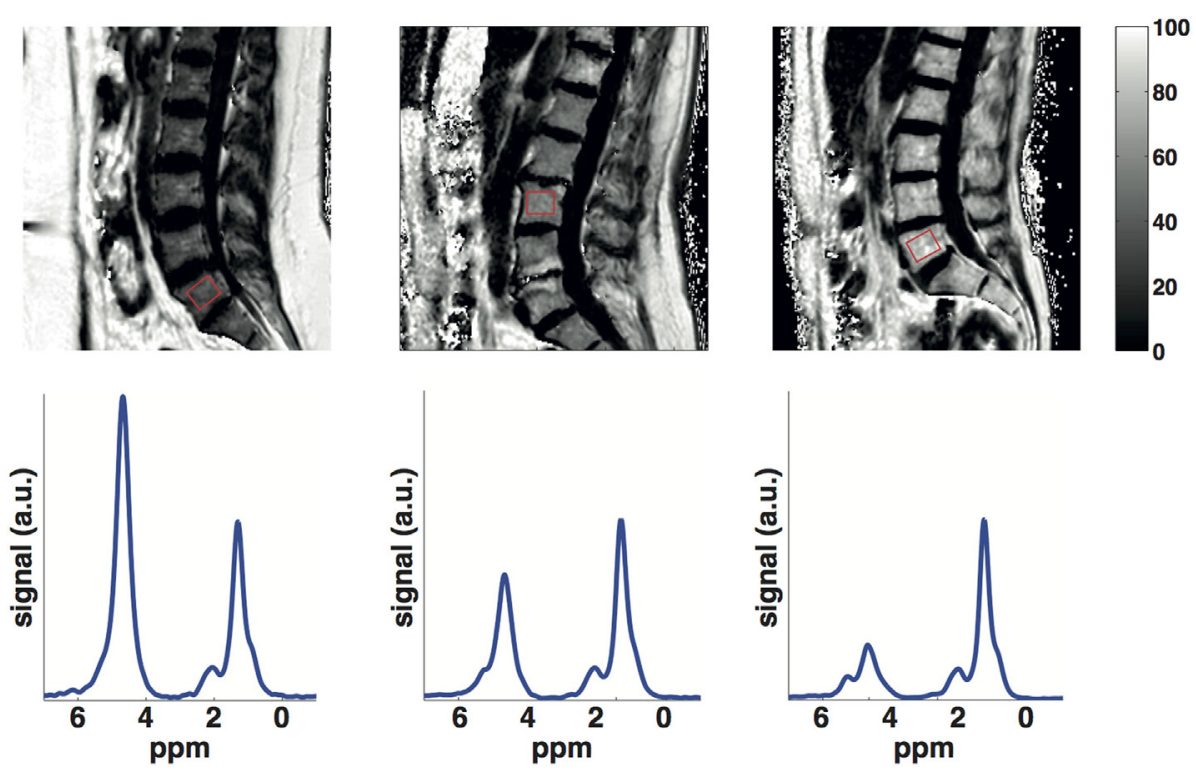

FIGURE 1 | Lumbar vertebral bone marrow PDFF maps (first row) and single-voxel MR spectra (second row) in a young subject (25 years), an old subject (60 years) with normal BMD (spine t-score $=3.7$ ) and an old subject $(60$ years) with osteoporosis (spine $t$-score $=-3$ ). Bone marrow PDFF increases with age and lower BMD: the young subject had a PDFF on the L5 vertebral body (red box) equal to $32.4 \%$, the old subject with normal BMD had a PDFF on the L3 vertebral body (red box) equal to $48.9 \%$ and the old subject with osteoporosis had a PDFF on the L5 vertebral body (red box) equal to $67.5 \%$.

by constraining the area of the olefinic fat peak to the main fat peaks (41-43). However, the quantification of fat unsaturation relies on the extraction of the olefinic fat peak on an individual spectrum basis and remains a major technical challenge in the presence of a strong water peak (i.e., in the spine). Previous studies measuring vertebral bone marrow fat unsaturation based on short-TE spectra have reported moderate reproducibility values (same day, with repositioning) (36). Increasing the TE (44) or adding diffusion-weighting $(45,46)$ have been recently proposed to reduce the water peak height and more robustly extract the olefinic peak in vertebral bone marrow spectra.

\section{Water-Fat Imaging}

In contrast to single-voxel MRS, chemical shift encoding-based water-fat imaging allows the spatially resolved assessment of the BMFF (Figure 1). High-resolution BMFF mapping is highly advantageous due to the heterogeneous distribution of bone marrow in most regions (e.g., proximal femur, spine). However, several confounding factors have to be considered when measuring bone marrow PDFF by using water-fat imaging, including the presence of multiple peaks in the fat spectrum $(47,48)$, T1-bias $(49,50)$ and $2^{*}$-decay effects $(47,51)$. The presence of trabecular bone most importantly shortens the $\mathrm{T} 2^{*}$ of water and fat components, inducing a rapid decay of the measured gradient echo signal with echo time $(42,52)$. After correcting for $\mathrm{T} 2{ }^{\star}$ decay effects, a good agreement was reported in vivo between MRSbased and imaging-based PDFF in both the proximal femur (42) and spine (52).

An ex vivo study was performed in trabecular bone specimens filled with water-fat emulsions of different fat fractions, showing an excellent agreement between imaging-based PDFF and the known PDFF of the emulsions (53). To validate the results of bone marrow water-fat imaging with a non-MRI reference, Arentsen et al. (54) and MacEwan et al. (55) performed studies comparing water-fat imaging with histological examinations. Water-fat imaging in both studies resulted in vertebral BMFF and water fraction values, which showed good correlation $(r=0.76-0.77)$ with the histological results.

As water-fat imaging methodologies become more broadly available, studies have been recently performed to evaluate the significance of a spatially resolved fat fraction map (56-60). In a recent study, Baum et al. investigated whole body spine water-fat imaging on 28 healthy subjects (56). They found an increased BMFF from the cervical to the lumbar level. Absolute precision error amounted to $1.7 \%$ on the average.

Despite a considerable amount of literature using MR methods to assess bone marrow properties in the pelvis and the long bones, vertebral bone marrow remains the region most extensively investigated in bone marrow studies of aging, osteoporosis, diabetes, and obesity (Table 1).

\section{Bone Marrow Fat in Aging}

The BMFF is well known to increase with age (Figure 1). The exact age dependence has been shown to differ between male and female subjects (61-63). A recent study has also emphasized the importance of T2-correction when using MRS to investigate the age dependence of BMFF (41). However, less is known about the age dependence of bone marrow fat unsaturation. Huovinen et al. recently investigated bone marrow fat unsaturation in young adults (15-27 years) (64). Thirty-five young adults from 27 to 35 years were included in their study, and they showed an increase of bone marrow fat unsaturation with age. The results 
TABLE 1 | Summary of MR-based studies investigating vertebral bone marrow fat properties in osteoporosis, diabetes, and obesity.

\begin{tabular}{|c|c|c|c|}
\hline Study & Subjects & $\begin{array}{l}\text { MR technique and bone } \\
\text { marrow fat parameters }\end{array}$ & Main results for bone marrow fat \\
\hline \multicolumn{4}{|l|}{ Osteoporosis } \\
\hline Yeung et al. (26) & 53 women & $\begin{array}{l}\text { MRS for fat fraction and } \\
\text { unsaturation }\end{array}$ & $\begin{array}{l}\text { Higher fat fraction and lower fat unsaturation in osteoporotic than osteopenic and normal } \\
\text { subjects }\end{array}$ \\
\hline Griffith et al. (19) & 90 men & MRS for fat fraction & Higher fat fraction in osteoporotic than osteopenic and normal subjects \\
\hline Griffith et al. (20) & 103 women & MRS for fat fraction & Higher fat fraction in osteoporotic than osteopenic and normal subjects \\
\hline Patsch et al. (66) & 69 women & $\begin{array}{l}\text { MRS for fat fraction and } \\
\text { unsaturation }\end{array}$ & Fat unsaturation negatively associated with prevalence of fragility fractures \\
\hline Kühn et al. (57) & 51 subjects & Water-fat imaging for PDFF & Higher PDFF in osteoporotic than normal subjects \\
\hline Karampinos et al. (21) & 10 specimens & MRS for fat fraction (ex vivo) & Fat fraction negatively associated with failure load \\
\hline \multicolumn{4}{|l|}{ Diabetes and obesity } \\
\hline Bredella et al. (70) & 47 women & MRS for fat fraction & Fat fraction positively associated with visceral fat volume \\
\hline Baum et al. (16) & 26 women & $\begin{array}{l}\text { MRS for fat fraction and } \\
\text { unsaturation }\end{array}$ & Fat unsaturation lower in diabetics compared to non-diabetics \\
\hline Bredella et al. (67) & 35 men & MRS for fat fraction & Fat fraction negatively associated with bone strength parameters \\
\hline Bredella et al. (68) & 106 women & MRS for fat fraction & Fat fraction positively associated with intra-hepatic and intramyocellar lipids \\
\hline Bredella et al. (69) & 79 women & MRS for fat fraction & Fat fraction increased after growth hormone therapy \\
\hline Cordes at al. (72) & 20 women & MRS for fat fraction & $\begin{array}{l}\text { Fat fraction unchanged after a 4-week calorie restriction in obesity, but fat fraction changes } \\
\text { associated with subcutaneous fat volume before intervention }\end{array}$ \\
\hline Schafer et al. (22) & 11 women & MRS for fat fraction & Fat fraction decreased only in diabetics after a gastric bypass surgery \\
\hline
\end{tabular}

suggest an association of bone marrow fat unsaturation with age in early adulthood and may represent the normal maturation of bone marrow.

\section{Bone Marrow Fat in Osteoporosis Bone Marrow Fat Fraction}

The MR-based vertebral bone marrow fat parameter studied most frequently in the context of osteoporosis is the fat fraction. Representative data from the authors own work, using a methodology similar to Baum et al. (65) and highlighting the effect of age and osteoporosis on bone-marrow fat fraction, are shown in Figure 1.

Most previous studies evaluating the relationship between BMD and BMFF have been based on single-voxel MRS. Griffith et al. performed a study in 103 female subjects to investigate the association between bone marrow fat and osteoporosis in vivo (20). They acquired DXA to stratify the group into healthy $(n=18)$, osteopenic $(n=30)$, and osteoporotic subjects $(n=55)$. MRS was performed at L3. The vertebral marrow fat fraction was significantly increased in osteoporotic subjects $(67.8 \pm 8.5 \%)$ compared with healthy subjects $(59.2 \pm 10.0 \%)$. Similar results were found in men. In another study, 90 men (42 subjects with normal BMD, 23 osteopenic, and 17 osteoporotic subjects) were recruited and obtained a measurement of the bone marrow fat content in L3 using MRS (19). The vertebral marrow fat fraction was significantly increased in subjects with osteoporosis $(58.2 \pm 7.8 \%)$ and osteopenia $(55.7 \pm 10.2 \%)$ compared to subjects with normal BMD $(50.5 \pm 8.7 \%)$.

Karampinos et al. recently examined ten vertebrae from human cadavers using MRS to assess BMFF, multi-detector computed tomography (MDCT) to determine BMD and trabecular bone microstructure parameters, and biomechanical testing to assess vertebral bone strength (21). They reported significant correlations between the MRS-based fat fraction and MDCTbased parameters (up to $r=-0.72$ ), and MRS-based fat fraction and vertebral failure load $(r=-0.77)$. Thus, this study demonstrated that bone marrow fat volume is negatively associated with both bone microstructure and bone strength. However, further studies with larger number of specimens are needed in order to investigate whether the BMFF has an effect on bone strength after correcting for the contribution of BMD.

Kühn et al. performed one of the first bone marrow high-resolution fat fraction mapping studies in patients with osteoporosis. Their study included 51 patients who underwent DXA as well as water-fat imaging of the lumbar spine (57). According to the DXA results, the participants were divided into three subgroups: 92 healthy, 47 osteopenic, and 34 osteoporotic. The obtained PDFF was greater in osteoporotic than healthy vertebrae $(62.4 \pm 11.0 \%$ versus $56.3 \pm 14.8 \%)$. Thus, water-fat imaging could be an alternative to the most commonly used MRS to assess bone marrow fat in the context of osteoporosis.

\section{Bone Marrow Fat Unsaturation}

The second MR-based bone marrow fat parameter, which has been linked to bone matrix loss, is bone marrow fat unsaturation. Yeung et al. analyzed bone marrow fat composition in the context of osteoporosis (26). They included 53 women over 60 years of age and 12 young controls in their study. The subjects underwent DXA and MRS of the lumbar spine. Interestingly, the fat unsaturation level was significantly decreased in osteoporotic $(0.091 \pm 0.013)$ and osteopenic $(0.097 \pm 0.014)$ subjects compared to healthy subjects $(0.114 \pm 0.016)$ and young controls $(0.127 \pm 0.031)$. Patsch et al. investigated the vertebral bone marrow fat composition in diabetic and non-diabetic postmenopausal women with and without fragility fractures (66). In consistency with Yeung et al., the prevalence of fragility fractures 
was associated with $-1.7 \%$ lower unsaturation levels and $+2.9 \%$ higher saturation levels.

\section{Bone Marrow Fat in T2DM}

Baum et al. performed a study on 26 subjects, including 13 non-diabetic and 13 treated diabetic women (16). The subjects underwent blood parameter analysis including plasma glucose and HbA1c. Images from mid T12 to mid L4 were acquired using MDCT to obtain SAT (subcutaneous adipose tissue), VAT (visceral adipose tissue), and TAT (total adipose tissue). MRS was obtained at L1, L2, and L3 to assess BMFF and unsaturation. The mean vertebral BMFF was similar in the diabetic women and the healthy controls $(69.3 \pm 7.5 \%$ versus $67.5 \pm 6.1 \% ; P>0.05)$. However, the mean unsaturation level was significantly lower in the diabetic group $(6.7 \pm 1.0 \%$ versus $7.9 \pm 1.6 \%$; $P<0.05)$. Adjusted SAT and TAT correlated significantly with mean vertebral bone marrow fat content in the whole study population $(r=0.538$ and $r=0.466 ; P<0.05)$. Interestingly, significant correlations of mean vertebral bone marrow fat content with adjusted VAT and $\mathrm{HbAlc}$ were observed only in the diabetic group $(r=0.642$ and $r=0.825$; $P<0.05)$.

Similar results to the study by Baum et al. (16) were reported by Patsch et al. (66): diabetes was associated with a $-1.3 \%$ lower unsaturation and $+3.3 \%$ higher saturation levels. Diabetics with fractures showed the lowest marrow unsaturation and highest saturation. Therefore, the authors suggested that vertebral bone marrow fat unsaturation beyond fat fraction might have a potential for assessing the BMD-independent fracture risk.

\section{Bone Marrow Fat in Obesity}

Bone marrow fat fraction has been shown to be a negative predictor of bone microarchitecture and mechanical properties in obese men (67). BMFF has been also shown to be positively associated with ectopic and serum lipid levels in obese men and women (68) and to increase after a 6-month growth hormone administration in obese women (69).

To get further insight into the relationship between bone marrow fat and obesity, Bredella et al. performed a study in 47 pre-menopausal women (70). The authors measured IGF-1 and growth hormone blood levels, and performed MRS at L4 and MDCT scans at the level of L4 for VAT determination. The vertebral BMFF was positively associated with VAT and inversely associated with IGF-1. The authors concluded that visceral fat might have detrimental effects on bone health, which may be mediated in part by IGF-1 as an important regulator of the fat and bone lineage. Wongdee et al. concluded in a recent review that obesity and insulin resistance because of hyperglycemia in T2DM may induce osteoblast and osteoclast dysfunction with a resulting lower bone turnover (71). However, the underlying cellular and molecular mechanisms of insulin resistance in osteoblasts, osteoclasts, and osteocytes remain unknown and require further investigation.

Cordes et al. examined a group of twenty obese women who underwent a 4 week calorie restriction of $800 \mathrm{kcal} / \mathrm{day}$ (72). They performed MRS of the bone marrow and liver. Furthermore, they determined blood fat values and acquired two-point Dixon images of the abdomen to measure SAT and VAT. Despite a significant reduction of the body mass index (BMI), SAT, VAT, triglycerides, and LDL (low density lipoproteins)-cholesterol, they observed no significant reduction of the vertebral BMFF. However, absolute BMFF changes were positively associated with SAT volume $(r=0.489)$ and negatively associated with non-adipose tissue volume $(r=-0.493)$ before dietary intervention (67).

Schafer et al. examined the changes of the BMFF and bone mass after gastric bypass surgery (22). They included eleven women (six diabetic, five non-diabetic) who underwent bariatric surgery (Roux-y-gastric-bypass) and underwent L3/L4 MRS, anthropometric measurements, whole body fat, and BMD measurements. VAT was determined on a single slice at the level of L4 using MDCT. In consistency with previous studies, they reported a positive correlation between age and bone marrow fat content. Interestingly, mean bone marrow fat decreased $(-7.5 \%, p=0.05)$ in the diabetic subjects, while the non-diabetic women showed only a small change $(+0.9 \%, p=0.84)$. Despite the small sample size, this study highlighted that bone marrow fat behaves differently compared to other fat depots in patients without diabetes after gastric bypass surgery.

\section{CONCLUSION AND PERSPECTIVES}

In summary, MR-based assessment of bone marrow fat provides interesting insights into the pathophysiology of osteoporosis, T2DM, and obesity as well as the association of bone and metabolic disturbances. Currently available MR methods including MRS and water-fat imaging enable the non-invasive extraction of the BMFF and unsaturation. Very little is known about the underlying mechanisms. Furthermore, new research questions are evolving on the role of bone marrow adipocytes in bone remodeling, hematopoietic stem cell differentiation, and whole body homeostasis $(73,74)$, on novel non-invasive MR biomarkers specific to the distribution, composition, microstructure, and function of bone marrow adipocytes requiring further investigations.

\section{AUTHOR CONTRIBUTIONS}

Collection of literature: CC, TB, and DK. Development of technical parts: MD, SR, MND, and DK. Development of clinical parts: CC, TB, HH, JK, and DK. Manuscript preparation/revision: CC, TB, MD, SR, MND, HH, JK, and DK.

\section{FUNDING}

This work has received funding from Philips Healthcare (to DK), the European Research Council (ERC) under the European Union's Horizon 2020 research and innovation programme [grant agreement No 677661, ProFatMRI (to DK)] and the Deutsche Forschungsgemeinschaft [DFG BA 4085/2-1 (to JK) and BA 4906/1-1 (to TB)]. This work was supported by the German Research Foundation (DFG) and the Technical University of Munich (TUM) in the framework of the Open Access Publishing Program. 


\section{REFERENCES}

1. Kanis JA. Assessment of fracture risk and its application to screening for postmenopausal osteoporosis: synopsis of a WHO report. Osteoporos Int (1994) 4:368-81. doi:10.1007/BF01622200

2. NIH Consensus. Development panel on osteoporosis prevention, diagnosis, and therapy, March 7-29 2000: highlights of the conference. South Med J (2001) 94(6):569-73. doi:10.1097/00007611-200106000-00005

3. Barcenilla-Wong AL, Chen JS, Cross MJ, March LM. The impact of fracture incidence on health related quality of life among community-based postmenopausal women. J Osteoporos (2015) 2015:717914. doi:10.1155/ 2015/717914

4. Bleibler F, Rapp K, Jaensch A, Becker C, König H-H. Expected lifetime numbers and costs of fractures in postmenopausal women with and without osteoporosis in Germany: a discrete event simulation model. BMC Health Serv Res (2014) 14:284. doi:10.1186/1472-6963-14-284

5. Ammann P, Rizzoli R. Bone strength and its determinants. Osteoporos Int (2003) 14(Suppl 3):S13-8. doi:10.1007/s00198-002-1345-4

6. Schuit S, van der Klift M, Weel AE, de Laet CE, Burger H, Seeman E, et al. Fracture incidence and association with bone mineral density in elderly men and women: the Rotterdam study. Bone (2004) 34:195-202. doi:10.1016/j. bone.2003.10.001

7. Baum T, Karampinos DC, Liebl H, Rummeny EJ, Waldt S, Bauer JS. Highresolution bone imaging for osteoporosis diagnostics and therapy monitoring using clinical MDCT and MRI. Curr Med Chem (2013) 20(38):4844-52. doi:1 $0.2174 / 09298673113206660279$

8. Krug R, Burghardt AJ, Majumdar S, Link TM. High-resolution imaging techniques for the assessment of osteoporosis. Radiol Clin North Am (2010) 48(3):601-21. doi:10.1016/j.rcl.2010.02.015

9. Wehrli FW, Song HK, Saha PK, Wright AC. Quantitative MRI for the assessment of bone structure and function. NMR Biomed (2006) 19(7):731-64. doi: $10.1002 / \mathrm{nbm} .1066$

10. Devlin MJ, Rosen CJ. The bone-fat interface: basic and clinical implications of marrow adiposity. Lancet Diabetes Endocrinol (2015) 3(2):141-7. doi:10.1016/ S2213-8587(14)70007-5

11. Fazeli PK, Horowitz MC, MacDougald OA, Scheller EL, Rodeheffer MS, Rosen CJ, et al. Marrow fat and bone - new perspectives. J Clin Endocrinol Metab (2013) 98(3):935-45. doi:10.1210/jc.2012-3634

12. Paccou J, Hardouin P, Cotten A, Penel G, Cortet B. The role of bone marrow fat in skeletal health: usefulness and perspectives for clinicians. J Clin Endocrinol Metab (2015) 100(10):3613-21. doi:10.1210/jc.2015-2338

13. Rosen CR, Bouxsein ML. Mechanisms of disease: is osteoporosis the obesity of bone? Nature (2006) 2:35-43. doi:10.1038/ncprheum0070

14. Schwartz AV. Marrow fat and bone: review of clinical findings. Front Endocrinol (2015) 6:40. doi:10.3389/fendo.2015.00040

15. Zhao LJ, Jiang H, Papasian CJ, Maulik D, Drees B, Hamilton J, et al. Correlation of obesity and osteoporosis: effect of fat mass on the determination of osteoporosis. J Bone Miner Res (2008) 23(1):17-29. doi:10.1359/jbmr.070813

16. Baum T, Yap SP, Karampinos DC, Nardo L, Kuo D, Burghardt AJ, et al. Does vertebral bone marrow fat content correlate with abdominal adipose tissue, lumbar spine bone mineral density, and blood biomarkers in women with type 2 diabetes mellitus? J Magn Reson Imaging (2012) 35(1):117-24. doi:10.1002/ jmri.22757

17. Cohen A, Shen W, Dempster DW, Zhou H, Recker RR, Lappe JM, et al. Marrow adiposity assessed on transiliac crest biopsy samples correlates with noninvasive measurement of marrow adiposity by proton magnetic resonance spectroscopy (1H-MRS) at the spine but not the femur. Osteoporos Int (2015) 26(10):2471-8. doi:10.1007/s00198-015-3161-7

18. Di Iorgi N, Rosol M, Mittelman SD, Gilsanz V. Reciprocal relation between marrow adiposity and the amount of bone in the axial and appendicular skeleton of young adults. JClin Endocrinol Metab (2008) 93(6):2281-6. doi:10.1210/jc.2007-2691

19. Griffith JF, Yeung DK, Antonio GE, Lee FK, Hong AW, Wong SY, et al. Vertebral bone mineral density, marrow perfusion, and fat content in healthy men and men with osteoporosis: dynamic contrast-enhanced MR imaging and MR spectroscopy. Radiology (2005) 236(3):945-51. doi:10.1148/ radiol.2363041425

20. Griffith JF, Yeung DK, Antonio GE, Wong SY, Kwok TC, Woo J, et al. Vertebral marrow fat content and diffusion and perfusion indexes in women with varying bone density: MR evaluation. Radiology (2006) 241(3):831-8. doi:10.1148/radiol.2413051858

21. Karampinos DC, Ruschke S, Gordijenko O, Grande Garcia E, Kooijman $\mathrm{H}$, Burgkart R, et al. Association of MRS-based vertebral bone marrow fat fraction with bone strength in a human in vitro model. J Osteoporos (2015) 2015:152349. doi:10.1155/2015/152349

22. Schafer AL, Li X, Schwartz AV, Tufts LS, Wheeler AL, Grunfeld C, et al. Changes in vertebral bone marrow fat and bone mass after gastric bypass surgery: a pilot study. Bone (2015) 74:140-5. doi:10.1016/j.bone.2015.01.010

23. Schellinger D, Lin CS, Lim J, Hatipoglu HG, Pezzullo JC, Singer AJ. Bone marrow fat and bone mineral density on proton MR spectroscopy and dualenergy X-ray absorptiometry: their ratio as a new indicator of bone weakening. AJR Am J Roentgenol (2004) 183(6):1761-5. doi:10.2214/ajr.183.6.01831761

24. Schwartz AV, Sigurdsson S, Hue TF, Lang TF, Harris TB, Rosen CJ, et al. Vertebral bone marrow fat associated with lower trabecular BMD and prevalent vertebral fracture in older adults. J Clin Endocrinol Metab (2013) 98(6):2294-300. doi:10.1210/jc.2012-3949

25. Shen W, Scherzer R, Gantz M, Chen J, Punyanitya M, Lewis CE, et al. Relationship between MRI-measured bone marrow adipose tissue and hip and spine bone mineral density in African-American and Caucasian participants: the CARDIA study. J Clin Endocrinol Metab (2012) 97(4):1337-46. doi:10.1210/jc.2011-2605

26. Yeung DK, Griffith JF, Antonio GE, Lee FK, Woo J, Leung PC. Osteoporosis is associated with increased marrow fat content and decreased marrow fat unsaturation: a proton MR spectroscopy study. J Magn Reson Imaging (2005) 22(2):279-85. doi:10.1002/jmri.20367

27. Scheller EL, Rosen CJ. What's the matter with MAT? Marrow adipose tissue, metabolism, and skeletal health. Ann N Y Acad Sci (2014) 1311:14-30. doi: $10.1111 /$ nyas. 12327

28. Compston JE, Flahive J, Hooven FH, Anderson FA Jr, Adachi JD, Boonen S, et al. Obesity, health-care utilization, and health-related quality of life after fracture in postmenopausal women: global longitudinal study of osteoporosis in women (GLOW). Calcif Tissue Int (2014) 94(2):223-31. doi:10.1007/ s00223-013-9801-z

29. Melton LJ III, Leibson CL, Achenbach SJ, Therneau TM, Khosla S. Fracture risk in type 2 diabetes: update of a population-based study. J Bone Miner Res (2008) 23(8):1334-42. doi:10.1359/jbmr.080323

30. Napoli N, Strotmeyer ES, Ensrud KE, Sellmeyer DE, Bauer DC, Hoffman AR, et al. Fracture risk in diabetic elderly men: the MrOS study. Diabetologia (2014) 57(10):2057-65. doi:10.1007/s00125-014-3289-6

31. Schwartz AV, Sellmeyer DE, Ensrud KE, Cauley JA, Tabor HK, Schreiner PJ. Older women with diabetes have an increased risk of fracture: a prospective study. J Clin Endocrinol Metab (2001) 86(1):32-8. doi:10.1210/jcem.86.1.7139

32. Vestergaard P, Rejnmark L, Mosekilde L. Relative fracture risk in patients with diabetes mellitus, and the impact of insulin and oral antidiabetic medication on relative fracture risk. Diabetologia (2005) 48(7):1292-9. doi:10.1007/ s00125-005-1786-3

33. Duque G. Bone and fat connection in aging bone. Curr Opin Rheumatol (2008) 20(4):429-34. doi:10.1097/BOR.0b013e3283025e9c

34. Bredella MA, Daley SM, Kalra MK, Brown JK, Miller KK, Torriani M. Marrow adipose tissue quantification of the lumbar spine by using dual-energy ct and single-voxel (1)H MR spectroscopy: a feasibility study. Radiology (2015) 277(1):230-5. doi:10.1148/radiol.2015142876

35. $\mathrm{Hu} \mathrm{HH}$, Kan HE. Quantitative proton MR techniques for measuring fat. NMR Biomed (2013) 26(12):1609-29. doi:10.1002/nbm.3025

36. Li X, Kuo D, Schafer AL, Porzig A, Link TM, Black D, et al. Quantification of vertebral bone marrow fat content using 3 tesla MR spectroscopy: reproducibility, vertebral variation, and applications in osteoporosis. J Magn Reson Imaging (2011) 33(4):974-9. doi:10.1002/jmri.22489

37. Bandirali M, Di Leo G, Papini GD, Messina C, Sconfienza LM, Ulivieri FM, et al. A new diagnostic score to detect osteoporosis in patients undergoing lumbar spine MRI. Eur Radiol (2015) 25(10):2951-9. doi:10.1007/s00330-015-3699-y

38. Shen W, Gong X, Weiss J, Jin Y. Comparison among T1-weighted magnetic resonance imaging, modified dixon method, and magnetic resonance spectroscopy in measuring bone marrow fat. J Obes (2013) 2013:298675. doi: $10.1155 / 2013 / 298675$

39. Griffith JF, Yeung DK, Chow SK, Leung JC, Leung PC. Reproducibility of MR perfusion and (1)H spectroscopy of bone marrow. J Magn Reson Imaging (2009) 29(6):1438-42. doi:10.1002/jmri.21765 
40. Singhal V, Miller KK, Torriani M, Bredella MA. Short- and long-term reproducibility of marrow adipose tissue quantification by $1 \mathrm{H}-\mathrm{MR}$ spectroscopy. Skeletal Radiol (2016) 45(2):221-5. doi:10.1007/s00256-015-2292-4

41. Dieckmeyer M, Ruschke S, Cordes C, Yap SP, Kooijman H, Hauner H, et al. The need for $\mathrm{T}(2)$ correction on MRS-based vertebral bone marrow fat quantification: implications for bone marrow fat fraction age dependence. $N M R$ Biomed (2015) 28(4):432-9. doi:10.1002/nbm.3267

42. Karampinos DC, Melkus G, Baum T, Bauer JS, Rummeny EJ, Krug R. Bone marrow fat quantification in the presence of trabecular bone: initial comparison between water-fat imaging and single-voxel MRS. Magn Reson Med (2014) 71(3):1158-65. doi:10.1002/mrm.24775

43. Hamilton G, Yokoo T, Bydder M, Cruite I, Schroeder ME, Sirlin CB, et al. In vivo characterization of the liver fat (1)H MR spectrum. NMR Biomed (2011) 24(7):784-90. doi:10.1002/nbm.1622

44. Bingolbali A, Fallone BG, Yahya A. Comparison of optimized long echo time STEAM and PRESS proton MR spectroscopy of lipid olefinic protons at 3 tesla. J Magn Reson Imaging (2015) 41(2):481-6. doi:10.1002/jmri.24532

45. Ruschke S, Kienberger H, Baum T, Kooijman H, Settles M, Haase A, et al. Diffusion-weighted stimulated echo acquisition mode (DW-STEAM) MR spectroscopy to measure fat unsaturation in regions with low proton-density fat fraction. Magn Reson Med (2016) 75(1):32-41. doi:10.1002/mrm.25578

46. Ruschke S, Dieckmeyer M, Kooijman H, Haase A, Rummeny EJ, Bauer JS, et al., editors. Separating water and olefinic fat peaks using diffusion-weighted MRS and diffusion constraint fitting to measure vertebral bone marrow fat unsaturation. Proc ISMRM (Toronto) (2015). 618 p.

47. Bydder M, Yokoo T, Hamilton G, Middleton MS, Chavez AD, Schwimmer JB, et al. Relaxation effects in the quantification of fat using gradient echo imaging. Magn Reson Imaging (2008) 26(3):347-59. doi:10.1016/j.mri.2007.08.012

48. Yu H, Shimakawa A, McKenzie CA, Brodsky E, Brittain JH, Reeder SB. Multiecho water-fat separation and simultaneous $\mathrm{R}_{2}{ }^{*}$ estimation with multifrequency fat spectrum modeling. Magn Reson Med (2008) 60(5):1122-34. doi: $10.1002 / \mathrm{mrm} .21737$

49. Karampinos DC, Yu H, Shimakawa A, Link TM, Majumdar S. T1-corrected fat quantification using chemical shift-based water/fat separation: application to skeletal muscle. Magn Reson Med (2011) 66:1312-26. doi:10.1002/mrm.22925

50. Liu CY, McKenzie CA, Yu H, Brittain JH, Reeder SB. Fat quantification with IDEAL gradient echo imaging: correction of bias from $\mathrm{T}_{1}$ and noise. Magn Reson Med (2007) 58(2):354-64. doi:10.1002/mrm.21301

51. Yu H, McKenzie CA, Shimakawa A, Vu AT, Brau AC, Beatty PJ, et al. Multiecho reconstruction for simultaneous water-fat decomposition and $\mathrm{T}_{2}{ }^{*}$ estimation. J Magn Reson Imaging (2007) 26(4):1153-61. doi:10.1002/jmri.21090

52. Karampinos DC, Ruschke S, Dieckmeyer M, Eggers H, Kooijman H, Rummeny EJ, et al. Modeling of $\mathrm{T} 2{ }^{*}$ decay in vertebral bone marrow fat quantification. NMR Biomed (2015) 28(11):1535-42. doi:10.1002/nbm.3420

53. Gee CS, Nguyen JT, Marquez CJ, Heunis J, Lai A, Wyatt C, et al. Validation of bone marrow fat quantification in the presence of trabecular bone using MRI. J Magn Reson Imaging (2015) 42(2):539-44. doi:10.1002/jmri.24795

54. Arentsen L, Yagi M, Takahashi Y, Bolan PJ, White M, Yee D, et al. Validation of marrow fat assessment using noninvasive imaging with histologic examination of human bone samples. Bone (2015) 72:118-22. doi:10.1016/j.bone.2014.11.002

55. MacEwan IJ, Glembotski NE, D'Lima D, Bae W, Masuda K, Rashidi HH, et al. Proton density water fraction as a biomarker of bone marrow cellularity: validation in ex vivo spine specimens. Magn Reson Imaging (2014) 32(9):1097-101. doi:10.1016/j.mri.2014.03.005

56. Baum T, Yap SP, Dieckmeyer M, Ruschke S, Eggers H, Kooijman H, et al. Assessment of whole spine vertebral bone marrow fat using chemical shift-encoding based water-fat MRI. J Magn Reson Imaging (2015) 42(4):1018-23. doi:10.1002/jmri.24854

57. Kuhn JP, Hernando D, Meffert PJ, Reeder S, Hosten N, Laqua R, et al. Protondensity fat fraction and simultaneous $\mathrm{R}^{*}$ estimation as an MRI tool for assessment of osteoporosis. Eur Radiol (2013) 23(12):3432-9. doi:10.1007/ s00330-013-2950-7

58. Li GW, Xu Z, Chen QW, Tian YN, Wang XY, Zhou L, et al. Quantitative evaluation of vertebral marrow adipose tissue in postmenopausal female using MRI chemical shift-based water-fat separation. Clin Radiol (2014) 69(3):254-62. doi:10.1016/j.crad.2013.10.005

59. Martin J, Nicholson G, Cowin G, Ilente C, Wong W, Kennedy D. Rapid determination of vertebral fat fraction over a large range of vertebral bodies. J Med Imaging Radiat Oncol (2014) 58(2):155-63. doi:10.1111/1754-9485.12143
60. Ojanen X, Borra RJ, Havu M, Cheng SM, Parkkola R, Nuutila P, et al. Comparison of vertebral bone marrow fat assessed by $1 \mathrm{H}$ MRS and inphase and out-of-phase MRI among family members. Osteoporos Int (2014) 25(2):653-62. doi:10.1007/s00198-013-2472-9

61. Griffith JF, Yeung DK, Ma HT, Leung JC, Kwok TC, Leung PC. Bone marrow fat content in the elderly: a reversal of sex difference seen in younger subjects. J Magn Reson Imaging (2012) 36(1):225-30. doi:10.1002/ jmri.23619

62. Ishijima $\mathrm{H}$, Ishizaka $\mathrm{H}$, Horikoshi $\mathrm{H}$, Sakurai M. Water fraction of lumbar vertebral bone marrow estimated from chemical shift misregistration on MR imaging: normal variations with age and sex. AJR Am J Roentgenol (1996) 167(2):355-8. doi:10.2214/ajr.167.2.8686603

63. Kugel H, Jung C, Schulte O, Heindel W. Age- and sex-specific differences in the $1 \mathrm{H}$-spectrum of vertebral bone marrow. J Magn Reson Imaging (2001) 13(2): 263-8. doi:10.1002/1522-2586(200102)13:2<263::AID-JMRI1038>3.3.CO;2-D

64. Huovinen V, Viljakainen H, Hakkarainen A, Saukkonen T, Toiviainen-Salo S, Lundbom $\mathrm{N}$, et al. Bone marrow fat unsaturation in young adults is not affected by present or childhood obesity, but increases with age: a pilot study. Metabolism (2015) 64(11):1574-81. doi:10.1016/j.metabol.2015.08.014

65. Baum T, Cordes C, Dieckmeyer M, Ruschke S, Franz D, Hauner H, et al. Assessment of whole spine vertebral bone marrow fat using chemical shift-encoding based water-fat MRI. J Magn Reson Imaging (2015) 42(4):1018-23. doi:10.1002/jmri.24854

66. Patsch JM, Li X, Baum T, Yap SP, Karampinos DC, Schwartz AV, et al. Bone marrow fat composition as a novel imaging biomarker in postmenopausal women with prevalent fragility fractures. J Bone Miner Res (2013) 28(8):17218. doi:10.1002/jbmr.1950

67. Bredella MA, Lin E, Gerweck AV, Landa MG, Thomas BJ, Torriani M, et al. Determinants of bone microarchitecture and mechanical properties in obese men. JClin Endocrinol Metab (2012) 97(11):4115-22. doi:10.1210/ jc.2012-2246

68. Bredella MA, Gill CM, Gerweck AV, Landa MG, Kumar V, Daley SM, et al. Ectopic and serum lipid levels are positively associated with bone marrow fat in obesity. Radiology (2013) 269(2):534-41. doi:10.1148/ radiol.13130375

69. Bredella MA, Gerweck AV, Barber LA, Breggia A, Rosen CJ, Torriani M, et al. Effects of growth hormone administration for 6 months on bone turnover and bone marrow fat in obese premenopausal women. Bone (2014) 62:29-35. doi:10.1016/j.bone.2014.01.022

70. Bredella MA, Torriani M, Ghomi RH, Thomas BJ, Brick DJ, Gerweck AV, et al. Vertebral bone marrow fat is positively associated with visceral fat and inversely associated with IGF-1 in obese women. Obesity (Silver Spring) (2011) 19(1):49-53. doi:10.1038/oby.2010.106

71. Wongdee K, Charoenphandhu N. Update on type 2 diabetes-related osteoporosis. World J Diabetes (2015) 6(5):673-8. doi:10.4239/wjd.v6.i5.673

72. Cordes C, Dieckmeyer M, Ott B, Shen J, Ruschke S, Settles M, et al. MR-detected changes in liver fat, abdominal fat, and vertebral bone marrow fat after a four-week calorie restriction in obese women. J Magn Reson Imaging (2015) 42(5):1272-80. doi:10.1002/jmri.24908

73. Hardouin P, Marie PJ, Rosen CJ. New insights into bone marrow adipocytes: report from the first European meeting on bone marrow adiposity (BMA 2015). Bone (2015). doi:10.1016/j.bone.2015.11.013

74. Scheller EL, Doucette CR, Learman BS, Cawthorn WP, Khandaker S, Schell B, et al. Region-specific variation in the properties of skeletal adipocytes reveals regulated and constitutive marrow adipose tissues. Nat Commun (2015) 6:7808. doi:10.1038/ncomms8808

Conflict of Interest Statement: DK receives Grant Support from Phillips Healthcare. The remaining authors declare that the research was conducted in the absence of any commercial or financial relationships that could be construed as a potential conflict of interest.

Copyright (c) 2016 Cordes, Baum, Dieckmeyer, Ruschke, Diefenbach, Hauner, Kirschke and Karampinos. This is an open-access article distributed under the terms of the Creative Commons Attribution License (CC BY). The use, distribution or reproduction in other forums is permitted, provided the original author(s) or licensor are credited and that the original publication in this journal is cited, in accordance with accepted academic practice. No use, distribution or reproduction is permitted which does not comply with these terms. 